\title{
Article \\ Effects of Al on Precipitation Behavior of Ti-Nb-Ta-Zr Refractory High Entropy Alloys
}

\author{
Jing Wen ${ }^{1,2, \dagger}$, Xin Chu ${ }^{2, \dagger}$, Yuankui Cao ${ }^{3, *(1)}$ and $\mathrm{Na} \mathrm{Li}^{3}$ \\ 1 Hunan Nonferrous Metals Vocational and Technical College, Zhuzhou 412006, China; wenjing@cumt.edu.cn \\ 2 College of Resources and Environmental Sciences, Hunan Normal University, Changsha 410081, China; \\ chuxin@hunnu.edu.cn \\ 3 State Key Laboratory of Powder Metallurgy, Central South University, Changsha 410083, China; \\ lina_csu@csu.edu.cn \\ * Correspondence: caoyuankui@csu.edu.cn; Tel.: +86-0731-88836296 \\ + First author.
}

check for updates

Citation: Wen, J.; Chu, X.; Cao, Y.; Li, N. Effects of $\mathrm{Al}$ on Precipitation Behavior of Ti-Nb-Ta-Zr Refractory High Entropy Alloys. Metals 2021, 11, 514. https://doi.org/10.3390/ met11030514

Academic Editor: Babak Shalchi Amirkhiz

Received: 20 February 2021

Accepted: 17 March 2021

Published: 20 March 2021

Publisher's Note: MDPI stays neutral with regard to jurisdictional claims in published maps and institutional affiliations.

Copyright: (c) 2021 by the authors. Licensee MDPI, Basel, Switzerland. This article is an open access article distributed under the terms and conditions of the Creative Commons Attribution (CC BY) license (https:/ / creativecommons.org/licenses/by/ $4.0 /)$.

\begin{abstract}
Addition of $\mathrm{Al}$ can decrease density and improve oxidation resistance of refractory high entropy alloys (RHEAs), but may cause complicated precipitation and further affect mechanical properties. The present work studied the microstructural evolution of Al-contained RHEAs at elevated temperatures. The effects of $\mathrm{Al}$ on precipitation behavior were discussed. Results show that, $\mathrm{TiNbTa}_{0.5} \mathrm{ZrAl}_{\mathrm{x}}$ alloys $(\mathrm{x} \leq 0.5$ ) have single BCC (Body Centered Cubic) structure, but the primary BCC phase is supersaturated. Precipitation of $\mathrm{BCC}_{(\mathrm{Nb}, \mathrm{Ta}) \text {-rich }}$ solid solution phase, $\mathrm{HCP}(\mathrm{Zr}, \mathrm{Al})$-rich intermetallic phase, and ordered B2 phase can occur during heat treatment at $600 \sim 1200{ }^{\circ} \mathrm{C}$. The precipitation of BCC2 phase mainly exists in RHEAs with low content of $\mathrm{Al}$, while HCP (Hexagonal Close Packed) precipitates prefer to form in RHEAs with high content of Al. Interestingly, ordered B2 precipitates with fine and basket-weave structure can form in $\mathrm{TiNbTa}_{0.5} \mathrm{ZrAl}_{0.5}$ alloy after annealing at $800{ }^{\circ} \mathrm{C}$, producing significant precipitation hardening effect.
\end{abstract}

Keywords: high entropy alloy; refractory metal; precipitation behavior; microstructure

\section{Introduction}

High entropy alloys (HEAs) are a new class of metallic material that consist of multiprincipal components but typically exhibit simple phase structure [1-3]. HEAs have many superior properties, such as high strength and toughness, good corrosion, and radiation resistance, mainly due to their flexible chemical compositions [4-6]. Refractory high entropy alloys (RHEAs) are a specific category of HEAs, which are primarily made up of high-melting-point elements, typically from group IV-VI in the periodic table [7-9]. RHEAs usually have single BCC structure because of the BCC structured components (elements from group V-VI are BCC structure and elements in group IV are also BCC structure at high temperatures). Most RHEAs possess high strength at high temperatures, making them a candidate for aerospace engineering, and have attracted extensive attention [10]. For example, the well-known WMoTaNb and WMoTaNbV RHEAs have yield strength above $400 \mathrm{MPa}$ up to $1600^{\circ} \mathrm{C}$, which were considered as potential substitution for nickel based superalloys [11]. But the heavy elements result in high density (usually $>10 \mathrm{~g} / \mathrm{cm}^{3}$ ), limiting their engineering application. Besides, some refractory metals, such as $\mathrm{V}$ and Mo, have poor high-temperature-oxidation resistance, making RHEAs difficult to work in atmosphere at high temperatures [12,13]. Addition of Al to RHEAs can effectively reduce density and improve oxidation resistance at the same time. For instance, Lin et al. [14] introduced $\mathrm{Al}$ into HfNbTaTiZr alloy and reduced its density from 9.96 to $8.84 \mathrm{~g} / \mathrm{cm}^{3}$. Bronislava et al. [13] introduced $\mathrm{Al}$ into TaMoCrTi alloy and found that the oxidation resistance improves significantly. Thus, alloying with $\mathrm{Al}$ may be a feasible approach for RHEAs to apply in aerospace engineering. 
Nevertheless, alloying with $\mathrm{Al}$ could lead to complex precipitation behavior in RHEAs. Yurchenko et al. [15] reported phase transformation in $\mathrm{Al}_{\mathrm{x}} \mathrm{NbTiVZr}$ RHEAs and found that the addition of $\mathrm{Al}$ leads to the formation of $\mathrm{C} 14$ Laves and $\mathrm{Zr}_{2} \mathrm{Al}$-type phases. Furthermore, the phase evolution in $\mathrm{Al}_{x} \mathrm{NbTiVZr}$ RHEAs is sensitive to the content of Al. Besides, they also found the addition of $\mathrm{Al}$ causes precipitation of another (Ti, $\mathrm{Al})$-rich orthorhombic phase in a $\mathrm{Ti}_{40} \mathrm{Nb}_{30} \mathrm{Hf}_{15}$ alloy [16]. Schuh et al. [17] introduced $\mathrm{Al}$ into TiVNb alloy and observed precipitation of $\mathrm{Nb}_{2} \mathrm{Al}$ and $\mathrm{Ti}_{3} \mathrm{Al}$ intermetallic phases. Ge et al. [18] studied phase equilibrium in Al-contained MoNbTaTiV RHEAs through CALPHAD method and presented that the Al-contained RHEAs have BCC structure at high temperatures but decomposed into multiphase structure (including BCC1, BCC2, $\mathrm{HCP}$, Sigma, and $\mathrm{Ti}_{3} \mathrm{Al}$ ) at intermediate temperatures. Apparently, addition of $\mathrm{Al}$ can induce formation of various second phases in RHEAs, and the precipitation behavior is relevant to the content of $\mathrm{Al}$ as well as the composition of the matrix. In our previous work [19], we have designed Ti-NbTa-Zr based RHEAs with good mechanical properties. In addition, we have demonstrated that the addition of $\mathrm{Al}$ can significantly enhance the high-temperature-oxidation resistance of the RHEAs [20]. However, the microstructural evolution of the Ti-Nb-Ta-Zr RHEAs with the addition of $\mathrm{Al}$ still remains unclear, which has become an urgent issue.

In this work, we fabricated a series of Al-contained Ti-Nb-Ta-Zr RHEAs and studied the microstructural evolution at elevated temperatures. The effects of $\mathrm{Al}$ on precipitation behavior were analyzed, and the detailed structures of the precipitates were characterized. The RHEAs were prepared through powder metallurgy method rather than conventional casting, so as to avoid severe chemical-segregation and make the analysis on precipitation behavior more precise.

\section{Experimental}

Elemental $\mathrm{Ti}, \mathrm{Nb}, \mathrm{Ta}, \mathrm{Zr}$, and $\mathrm{Al}$ powders with purities above $99.5 \%$ and average particle sizes of $18-42 \mu \mathrm{m}$ were used to prepare the $\operatorname{TiNbTa}_{0.5} \mathrm{ZrAl}_{\mathrm{X}}(\mathrm{X}=0,0.2,0.5,1.0)$ alloys through powder metallurgy method. The alloys were named "RHEA-Al0," "RHEA-Al0.2," "RHEA-A10.5," and "RHEA-Al1.0," respectively. The powders were blended under argon atmosphere for $10 \mathrm{~h}$ in a V-type mixture machine (Zgsujia V-20, Yupan, Nanjing, China). The powder mixtures were compressed via cold isostatic pressing (CIP) at a pressure of $200 \mathrm{MPa}$. Then, the compressed compacts were sintered at $1400{ }^{\circ} \mathrm{C}$ for $10 \mathrm{~h}$ in a vacuum of $1 \times 10^{-3} \mathrm{~Pa}$ followed by furnace cooling. To investigate precipitation behavior of the RHEAs, the as-sintered samples were cut into pieces and subjected to annealing at different temperatures. The pieces were encapsulated in quartz tubes and annealed at $600 \sim 1200{ }^{\circ} \mathrm{C}$ for $2 \mathrm{~h}$, and then quenched in water to retain the microstructural characteristics.

The phase constitution, microstructures, and micro-hardness were studied to investigate the precipitation behavior of the RHEAs. The phase analysis was per-formed using X-ray diffraction (XRD, Advance D8, RigakuD, Tokyo, Japan) with CuK $\alpha$ radiation. Microstructures were observed using a scanning electron microscope (SEM, Helios NanoLab G3 UC, FEI, Hillsboro, OR, USA) equipped with a backscatter electron (BSE) detector and an energy-dispersive $X$-ray spectroscopy (EDS). The chemical composition was analyzed by EDS. The details of microstructures were studied using a trans-mission electron microscope (TEM, Titan G260-300,FEI, Hillsboro, OR, USA). Specimens for TEM test were prepared using focused ion beam (FIB) apparatus (FEI, Hillsboro, OR, USA). The micro-hardness was measured using an indentation tester (BUEHLER5104, BUEHLER, Lake Bluff, IL, USA).

\section{Results}

The XRD patterns and microstructures of the as-sintered RHEAs are shown in Figure 1. RHEA-Al0, RHEA-Al0.2, and RHEA-Al0.5 all exhibit single BCC phase structure, while RHEA-Al1.0 shows BCC + HCP dual-phase structure. The HCP phase can be identified as $\mathrm{Zr}_{5} \mathrm{Al}_{4}$ phase according to its diffraction peaks. Figure $1 \mathrm{~b}-\mathrm{e}$ presents the microstructures of as-sintered RHEAs with different Al content. Obviously, RHEA-Al0, RHEA-A10.2, and RHEA-Al0.5 are single phase, and the microstructures are homogeneous. The contrasts of 
the BSE images are uniform, indicating that the chemical components distribute uniformly in the alloys. RHEA-Al1.0 has a BCC matrix and HCP precipitates. The HCP phase is quasi-continuous at grain boundaries but forms needlelike morphology inside grains. The microstructures indicate that the addition of Al can lead to formation of an HCP structured $\mathrm{Zr}_{5} \mathrm{Al}_{4}$ intermetallic phase. Figure 2 shows detailed phase structure of the as-sintered RHEAs obtained by TEM. As a representative, RHEA-A10.2 was characterized to analyze the BCC phase, since the three (RHEA-A10, RHEA-A10.2, and RHEA-A10.5) have similar phase structures. The bright field (BF) image presents the BCC phase without any precipitate, and the inserted selected area electron diffraction (SAED) patterns further verify the single BCC structure. The high-resolution TEM (HRTEM) image shows that the BCC phase is disordered solid solution phase, and the interplanar spacing is measured as $\mathrm{d}=0.242 \mathrm{~nm}$ for the crystal plane of (110). Figure 2c shows the BF image of RHEA-Al1.0 and the chemical composition of the HCP phase. The interface between the BCC matrix and the $\mathrm{HCP}$ precipitate is clear without any visible second phase. The chemical composition shows that the $\mathrm{HCP}$ phase is not a conventional $\mathrm{Zr}_{5} \mathrm{Al}_{4}$ intermetallic compound, instead, it also contains a small amount of $\mathrm{Ti}, \mathrm{Nb}$, and $\mathrm{Ta}$, indicating a multiple $\mathrm{Zr}_{5} \mathrm{Al}_{4}$ type intermetallic phase. The SAED patterns of the intermetallic phase further verify its HCP structure.
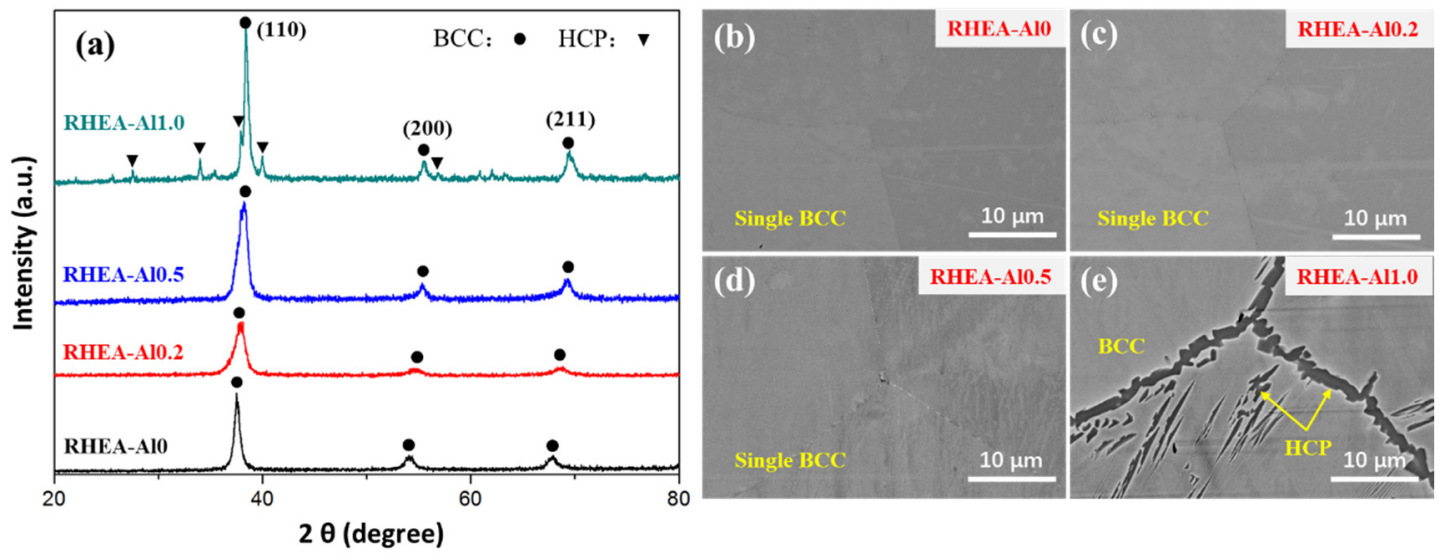

Figure 1. XRD patterns and microstructures of the as-sintered refractory high entropy alloys (RHEAs): (a) XRD patterns of the as-sintered RHEAs, (b) BSE image of RHEA-A10, (c) BSE image of RHEA-A10.2, (d) BSE image of RHEA-A10.5, and (e) BSE image of RHEA-Al1.0.

The phase constitutions of the RHEAs after annealing are shown in Figure 3. Apparently, addition of $\mathrm{Al}$ has strong impact on phase transformation of the annealed RHEAs. As for RHEA-Al0, annealing at temperatures above $1000{ }^{\circ} \mathrm{C}$ can maintain single BCC structure, while annealing at temperatures below $800^{\circ} \mathrm{C}$ leads to phase decomposition and forms a BCC2 phase. The diffraction peaks of the BCC2 phase are very close to those of the primary BCC phase, indicating their lattice parameters should also be similar. RHEAAl0.2 has analogous precipitation behavior with RHEA-A10, as shown in Figure 3b, but the temperature for maintaining single BCC structure is higher $\left(1200{ }^{\circ} \mathrm{C}\right)$ than that for RHEA-Al0, which means addition of Al can stimulate phase decomposition in the RHEAs. As for RHEA-A10.5, the precipitation behavior becomes more complicated. Annealing at $800{ }^{\circ} \mathrm{C}$ could also lead to phase decomposition and forms the BCC2 phase, but annealing at $1000 \sim 1200{ }^{\circ} \mathrm{C}$ results in precipitation of an $\mathrm{HCP}$ phase, which was identified as the $\mathrm{Zr}_{5} \mathrm{Al}_{4}$ type intermetallic phase. The precipitation behavior of RHEA-Al1.0 is rather simplex. Additionally, the results show same phase constitutions at $600 \sim 1200{ }^{\circ} \mathrm{C}$. The annealed RHEA-Al1.0 consists of BCC and HCP phases, and the intensity of the diffraction peaks of the HCP phase increases with the increasing annealing temperature, indicating a further precipitation of the $\mathrm{HCP} \mathrm{Zr}_{5} \mathrm{Al}_{4}$ type intermetallic phase. 
(a)
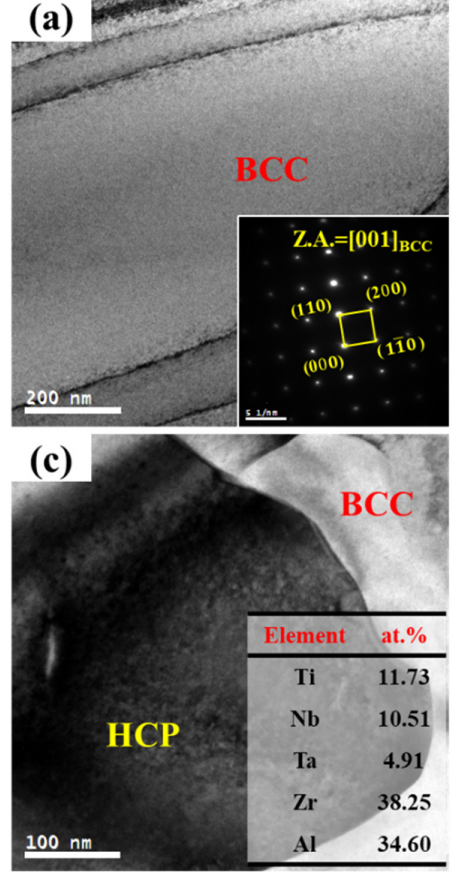

(b)
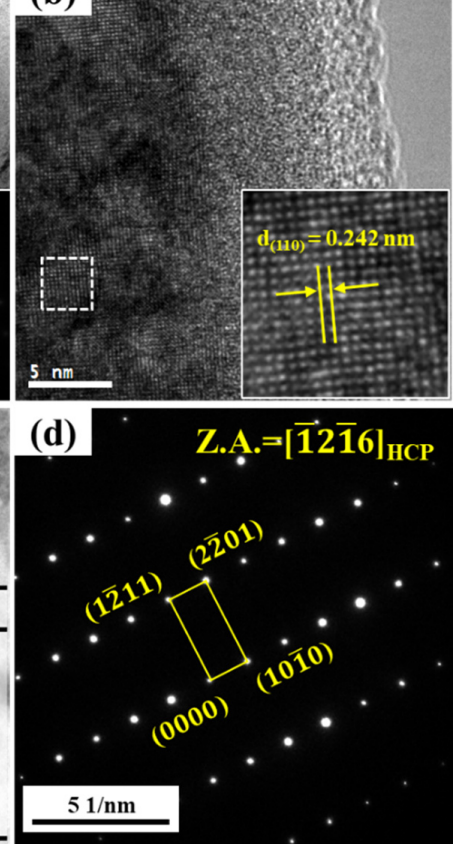

Figure 2. Detailed phase structure obtained by TEM: (a) bright field (BF) image of BCC phase in RHEA-A10.2 (inserted image gives the corresponding selected area electron diffraction (SAED) patterns), (b) high-resolution TEM (HRTEM) image of BCC phase in RHEA-Al0.2 (inserted image is the magnified view of the marked region), (c) BF image of RHEA-Al1.0 (inserted table gives the composition of the HCP phase), and (d) SAED patterns of the HCP phase in RHEA-Al1.0.
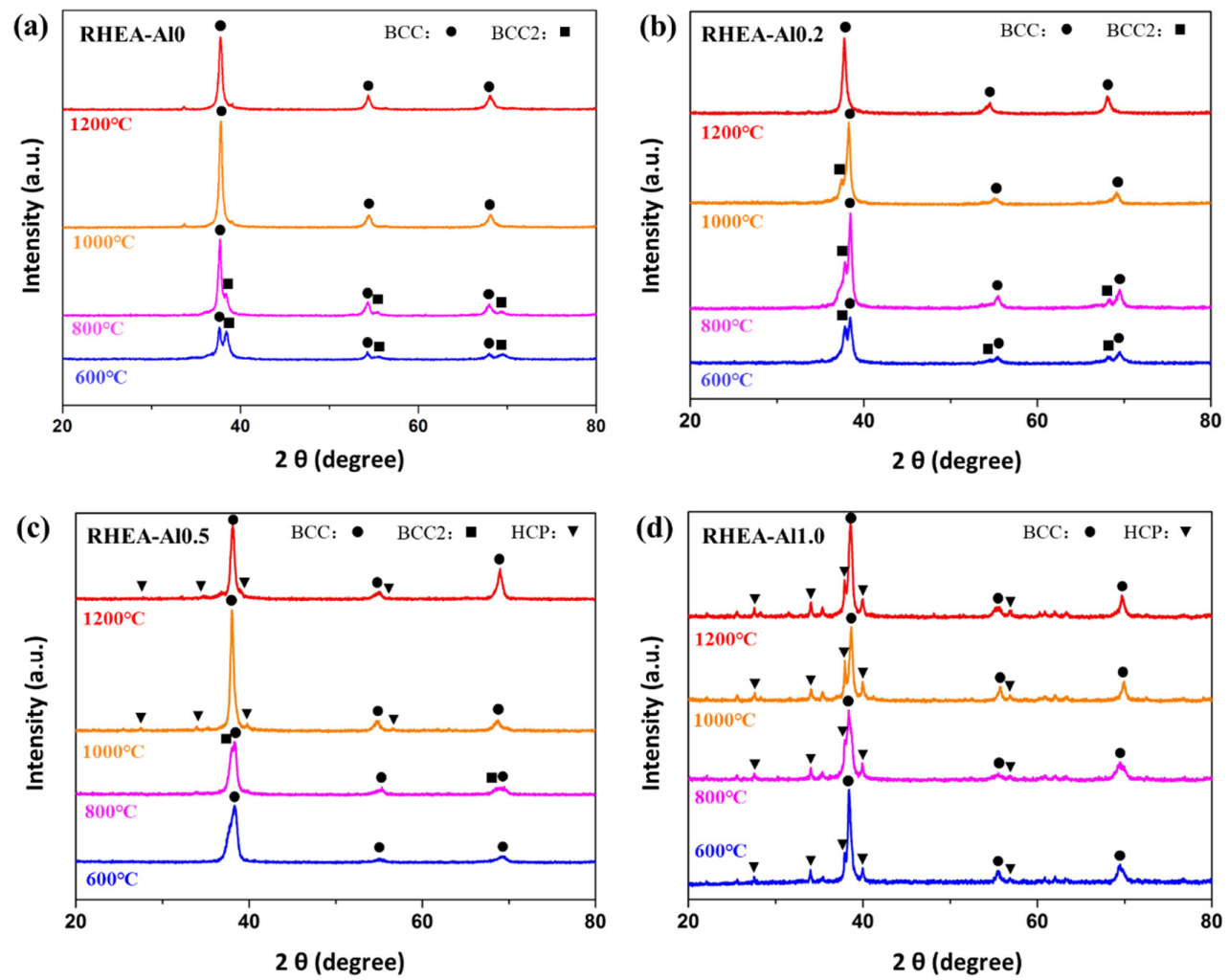

Figure 3. XRD patterns of the RHEAs annealed at $600 \sim 1200^{\circ} \mathrm{C}$ for $2 \mathrm{~h}$ : (a) RHEA-Al0, (b) RHEA-Al0.2, (c) RHEA-Al0.5, and (d) RHEA-Al1.0. 
Figure 4 presents microstructures of the RHEAs annealed at $600 \sim 1200{ }^{\circ} \mathrm{C}$, which gives a direct comparison of the precipitation characteristics. As for RHEA-Al0 and RHEA-A10.2, annealing at $600 \sim 1000{ }^{\circ} \mathrm{C}$ causes phase decomposition and forms the BCC2 phase. The BCC2 phase primarily distributes around grain boundaries in RHEA-A10, but forms both around grain boundaries and inside grains in RHEA-A10.2. The BCC2 phase was identified as $(\mathrm{Nb}, \mathrm{Ta})$-rich precipitates, while the BCC phase was identified as $\mathrm{Zr}$-rich matrix. The $(\mathrm{Nb}, \mathrm{Ta})$-rich precipitates become coarser with annealing temperature increasing. As for RHEA-Al0.5, annealing at $800{ }^{\circ} \mathrm{C}$ results in a fine, basket-weave, nano-lamellar structure inside the grain, which can be regarded as BCC and B2 phases. Similar structure has also been observed by Senkov et al. [21] in a $\mathrm{AlMo}_{0.5} \mathrm{NbTa}_{0.5} \mathrm{TiZr}$ RHEA. The B2 precipitates are too fine to analyze using SEM, which are carefully investigated using TEM below. Annealing at $1000 \sim 1200{ }^{\circ} \mathrm{C}$ leads to a formation of needle-like (Zr, Al)-rich HCP precipitates. The precipitates are fine and distribute homogeneously when RHEA-A10.5 annealed at $1000^{\circ} \mathrm{C}$. With annealing temperature increasing to $1200^{\circ} \mathrm{C}$, the precipitates become coarser. The precipitation behavior of RHEA-Al1.0 is much more simplex compared with others. Annealing at $600 \sim 1200^{\circ} \mathrm{C}$ results in further precipitation of (Zr, Al)-rich HCP precipitates, while the phase transformation of BCC2 is restrained. The microstructural characteristics of the annealed RHEAs are in good accordance with the XRD results. Figure 5 shows detailed structures of the B2 precipitates in RHEA-A10.5 after annealing at $800{ }^{\circ} \mathrm{C}$. The B2 precipitates have needle-like morphology with length of 10 50 nm and width below $10 \mathrm{~nm}$. The SAED patterns show a crystal orientation of $[001]_{\mathrm{B} 2} / /[001]_{\mathrm{BCC}}$. The $(001)_{\mathrm{B} 2}$ super-lattice reflections indicate that the B2 phase has an ordered crystal structure. The HRTEM image reveals that the B2 phase is coherent with the BCC phase. The inserted images give magnified view of the atoms, which present an ordered arrangement for B2 phase (note the brightness variation), and the corresponding Fast Fourier Transform (FFT) images also indicate ordered structure for B2 phase (note the diffraction spot of (010) plane, which should not exist in disordered BCC phase), further demonstrating that the B2 phase is ordered, agreeing with the observations by Senkov et al. [21,22].
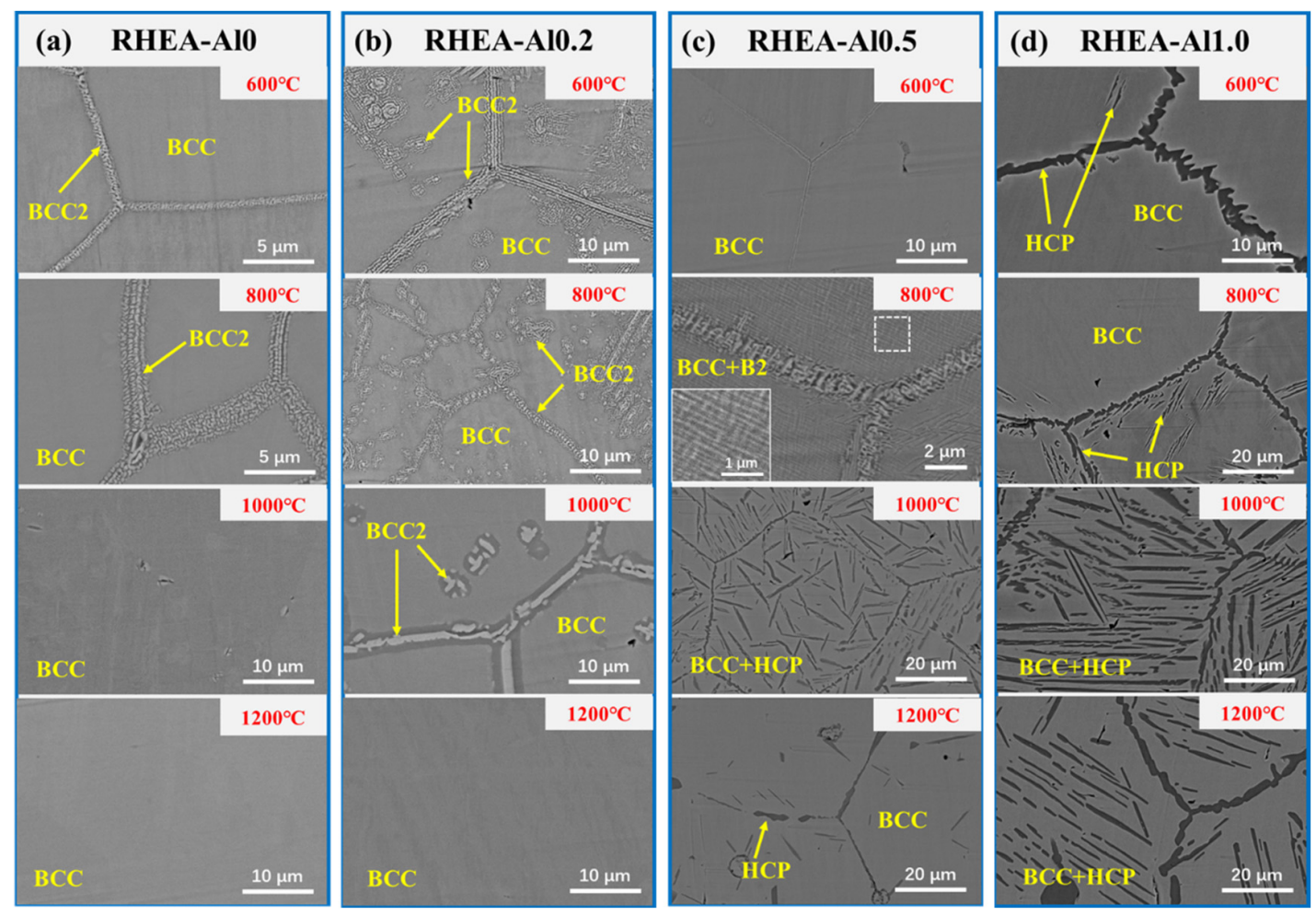

Figure 4. Microstructures of the RHEAs annealed at $600 \sim 1200^{\circ} \mathrm{C}$ for 2 h: (a) RHEA-Al0, (b) RHEA-Al0.2, (c) RHEA-Al0.5, and (d) RHEA-Al1.0. 

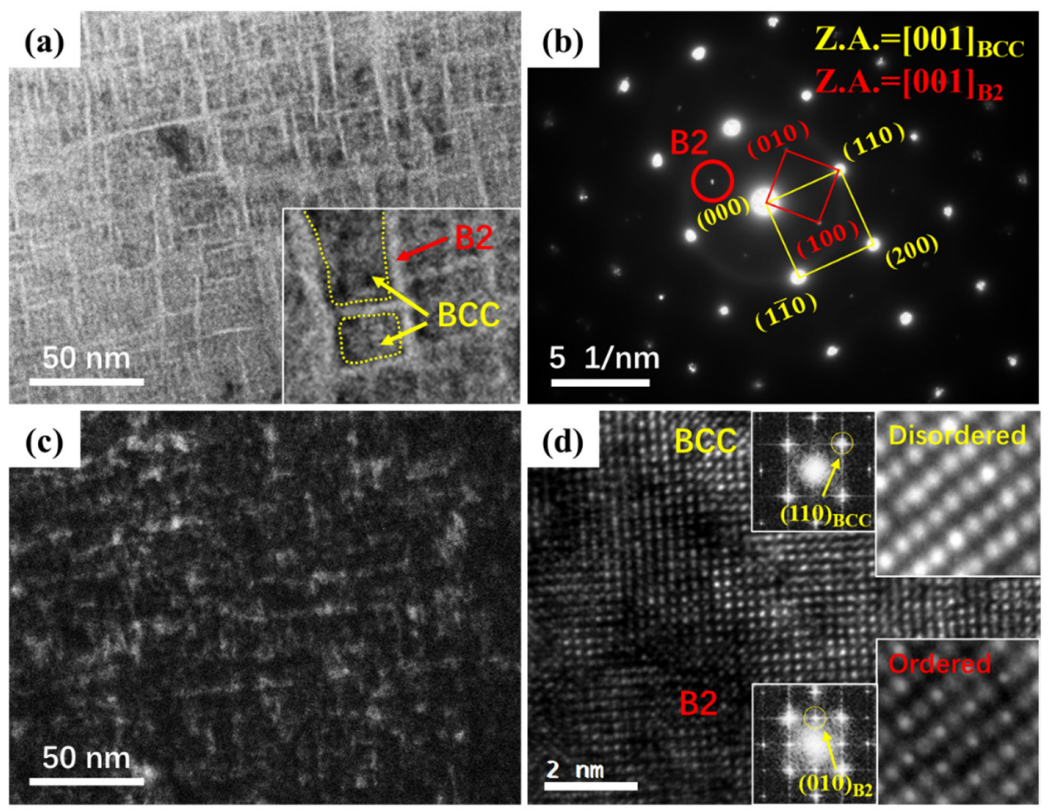

Figure 5. Detailed structures of the precipitates in RHEA-Al0.5 annealed at $800{ }^{\circ} \mathrm{C}$ for $2 \mathrm{~h}$ : (a) BF image of the precipitates, (b) SAED patterns of the RHEA-A10.5, (c) DF image of the precipitates, (d) HRTEM image of the precipitates (inserted images are the magnified view of the atoms and corresponding Fast Fourier Transform (FFT) patterns).

Precipitation could remarkably affect mechanical properties of RHEAs and typically causes hardening effect. The hardness of the current Al-contained RHEAs at different annealing status is shown in Figure 6. Apparently, the RHEAs become harder with the $\mathrm{Al}$ content increasing, mainly due to solid solution hardening. As for RHEA-Al0 and RHEA-A10.2, the precipitation of BCC2 phase (annealing at $600 \sim 800{ }^{\circ} \mathrm{C}$ ) causes increase in hardness. But, annealing above $1000^{\circ} \mathrm{C}$ makes the RHEAs transform back to single BCC structure, resulting in decreasing in hardness. As for RHEA-Al0.5 and RHEA-Al1.0, the precipitation of HCP phase also causes hardening. In addition, it can be noted that the hardness reaches the maximum values when the RHEAs are annealed at $1000{ }^{\circ} \mathrm{C}$, mainly because of the fine and dispersive $\mathrm{HCP}$ precipitates. Annealing at $1200{ }^{\circ} \mathrm{C}$ causes coarsening and dissolution of the HCP phase, leading to the decrease in hardness. It can also be noted that the hardness of RHEA-A10.5 increases remarkably when annealing at $800^{\circ} \mathrm{C}$, indicating that the ordered $\mathrm{B} 2$ phase has significant precipitation hardening effect.

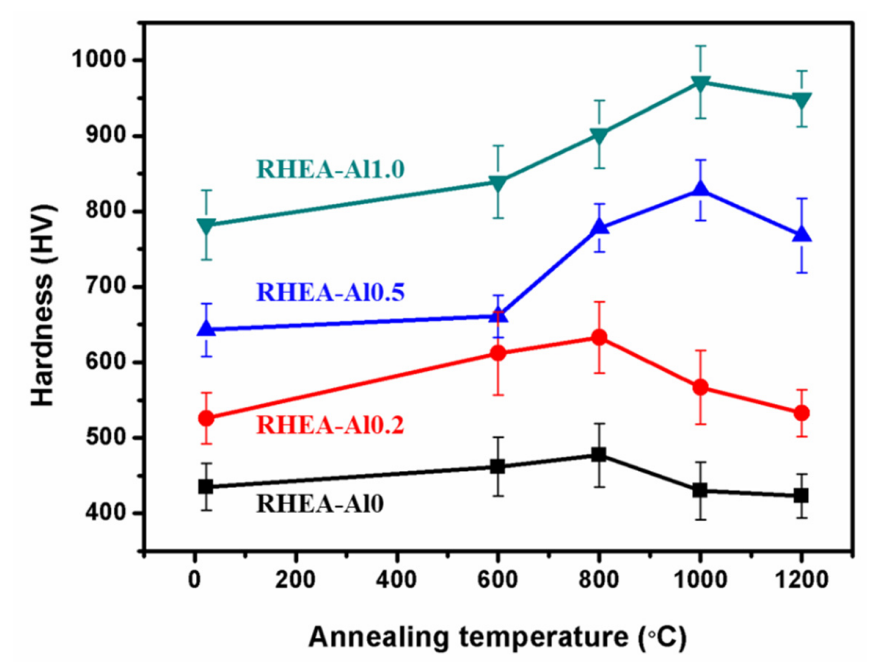

Figure 6. Hardness of the Al-contained RHEAs at different annealing status. 


\section{Discussion}

RHEAs normally form solid solution phase with single BCC structure when being prepared by casting method, because the solid solution phase can be stabilized by high entropy effect at high temperatures and possible phase transformation or precipitation could be kinetically hindered during rapid solidification process [8,23]. Similarly, RHEAs synthesized by high-temperature sintering also have single BCC structure. When being cooled down to room temperature, the cooling rate is too fast for RHEAs to accomplish possible phase transformation, therefore, forming supersaturated solid solution phase. The supersaturated BCC phase may decompose or transform to various second phases when subjected to annealing at intermediate temperatures and, consequently, affect the mechanical properties of RHEAs. Phase equilibrium of RHEAs can be described by several empirical parameters, such as the atomic size mismatch $(\delta)$ [24], the enthalpy of mixing $\left(\Delta H_{m i x}\right)$ [25], the parameter $\Omega[26,27]$, and the valence electron concentration (VEC) [26,27]. The $\delta$ and $\Delta H_{\text {mix }}$ can be expressed as [24,25]:

$$
\begin{gathered}
\delta=\sqrt{\sum_{i=1}^{n} c_{i}\left(1-r_{i} / \bar{r}\right)^{2}} \\
\Delta H_{\text {mix }}=4 \sum_{i=1, i \neq j}^{n} \Delta H_{i j}^{m i x} c_{i} c_{j},
\end{gathered}
$$

where $c_{i}$ is the molar ratio of $i$ th element, $r_{i}$ is the atomic radius of $i$ th element, $\bar{r}$ is the average radius, given by $\bar{r}=\sum_{i=1}^{n} c_{i} r_{i}$, and $\Delta H_{i j}^{\text {mix }}$ is the enthalpy of mixing between $i$ th and $j$ th elements. The parameter $\delta$ describes the comprehensive effect of the atomic-size difference in the multicomponent alloy, while $\Delta H_{\text {mix }}$ reflects the tendency of forming stable intermetallic compounds. It was proposed that $\delta \leq 6.6 \%$ and $-15 \leq \Delta H_{m i x} \leq 5 \mathrm{~kJ} / \mathrm{mol}$ can be used as criterion for forming solid solution phase of HEAs [28]. The parameter $\Omega$ and $V E C$ can be expressed as [26,27]:

$$
\begin{gathered}
\Omega=\frac{T_{m} \Delta S_{\text {mix }}}{\left|\Delta H_{\text {mix }}\right|} \\
V E C=\sum_{i=1}^{n} c_{i}(V E C)_{i},
\end{gathered}
$$

where $T_{m}$ is the average melting temperature, given by $T_{m}=\sum_{i=1}^{n} c_{i}\left(T_{m}\right)_{i}$, and $\Delta S_{\text {mix }}$ is the entropy of mixing of the alloy system, given by $\Delta S_{\text {mix }}=-\mathrm{R} \sum_{i=1}^{n} c_{i} \ln c_{i}, \mathrm{R}$ is the gas constant $(\mathrm{R}=8.314 \mathrm{~J} / \mathrm{K} / \mathrm{mol})$, and $(V E C)_{\mathrm{i}}$ is the $V E C$ of $i$ th element. The parameter $\Omega$ reflects the impact of entropy effect and enthalpy effect, i.e., a high value of $\Omega$ indicates a dominant impact of entropy effect, while a low value of $\Omega$ means a dominant impact of enthalpy effect. Solid solution phase is suggested existing at $\Omega>1.1$ [28]. The $V E C$ act as an efficient parameter to predict phase structure of most of HEAs, and it is suggested that single BCC phase exists at $V E C<6.87$ [27].

The above empirical parameters for the current $\mathrm{TiNbTa}_{0.5} \mathrm{ZrAl}_{\mathrm{x}}$ RHEAs were calculated and shown in Figure 7. The $\delta$ increases with increasing $\mathrm{Al}$ content and reaches the maximum value at $x=0.75$. Noted that all the values of $\delta$ are below $6.6 \%$, indicating the atomic size mismatch has limited effect on the precipitation behavior. The $\Delta H_{\text {mix }}$ decreases with increasing $\mathrm{Al}$ content and reaches the threshold value for intermetallic phase at $\mathrm{x}=0.75$, which means that an excess addition of $\mathrm{Al}$ can lead to the formation of intermetallic phase. The phase equilibrium based on the calculation of enthalpy of mixing agrees well with the experimental results, demonstrating that the precipitation of $\mathrm{HCP} \mathrm{Zr}_{5} \mathrm{Al}_{4}$ type intermetallic phase may be primarily induced by enthalpy effect. The values of $\Delta H_{\text {mix }}$ for atomic pairs between elements in Ti-Nb-Ta-Zr-Al system are given in Table 1 [14]. Obviously, the $\Delta H_{\text {mix }}$ between refractory elements is positive, but $\mathrm{Al}$ has large negative $\Delta H_{\text {mix }}$ with other refractory elements, especially with $\mathrm{Zr}$, therefore, leading to the formation of $\mathrm{Zr}$-Al intermetallic phase. Figure 7c exhibits the trend of parameter $\Omega$ with $\mathrm{Al}$ content increasing. When the $\mathrm{Al}$ content is low, the value of $\Omega$ is 
high, which means that the entropy effect takes the dominant control of phase transformation in the RHEAs. According to the basic relation, $\Delta G_{\text {mix }}=\Delta H_{\text {mix }}-\mathrm{T} \Delta S_{\text {mix }}$, such phase transformation behavior is temperature-dependent. Specifically, when at high temperature, the high entropy can lead to low $\Delta G_{m i x}$, thus stabilizing solid solution phase, but at low temperature, the high entropy has limited stabilizing effect, and therefore, phase decomposition may occur. The precipitation of BCC2 phase in RHEA-Al0 and RHEA-Al0.2 after annealing at $600 \sim 800{ }^{\circ} \mathrm{C}$ could be explained by the weakened stabilizing effect of high entropy. Figure $7 \mathrm{~d}$ presents the $V E C$ values of the Al-containing RHEAs, and all values are below 6.87. According to the empirical criterion, the calculated results indicate a BCC structure of the solid solution phase, which is consistent with the experimental observations. However, the above empirical parameters seem weak to explain the phase transformation in RHEA-A10.5, which exhibit strong temperature dependence. Soni et al. [29] also observed similar phase transformation behavior in a $\mathrm{Al}_{0.5} \mathrm{NbTa}_{0.8} \mathrm{Ti}_{1.5} \mathrm{~V}_{0.2} \mathrm{Zr}$ RHEA at $600-1200{ }^{\circ} \mathrm{C}$, and the corresponding mechanisms were seemingly relating to miscibility gap and spinodal decomposition. Besides, it is interesting that, RHEA-Al0.5 annealing at $800{ }^{\circ} \mathrm{C}$ causes precipitation of an ordered B2 phase. The structure, morphology, and distribution of $\mathrm{B} 2$ precipitates in RHEA-Al0.5 are analogous to those found in $\mathrm{AlMo}_{0.5} \mathrm{NbTa}_{0.5} \mathrm{TiZr}$ RHEA [21,22]. The precipitation behavior of $\mathrm{B} 2$ phase is associated with spinodal decomposition, and a proper content of $\mathrm{Al}$ can further lead to the ordered structure. The spinodal decomposition produces periodic compositional wave in the primary $\mathrm{BCC}$ phase, and upon further cooling forming the fine and basket-weave $B C C+B 2$ structure [21]. Soni et al. [30] further investigated phase inversion behavior of a $\mathrm{BCC}+\mathrm{B} 2$ RHEA and found that the continuous channel-like B2 phase can transform into discrete precipitates after long-term annealing at $600^{\circ} \mathrm{C}$. The phase inversion was explained by reduction in elastic strain energy as well as interfacial energy of the system. The annealed microstructure with continuous BCC matrix phase and discrete B2 precipitates could achieve good combination of ductility and strength. Therefore, the current RHEA-A10.5 RHEA was believed to have aging potential for attaining superior mechanical properties.
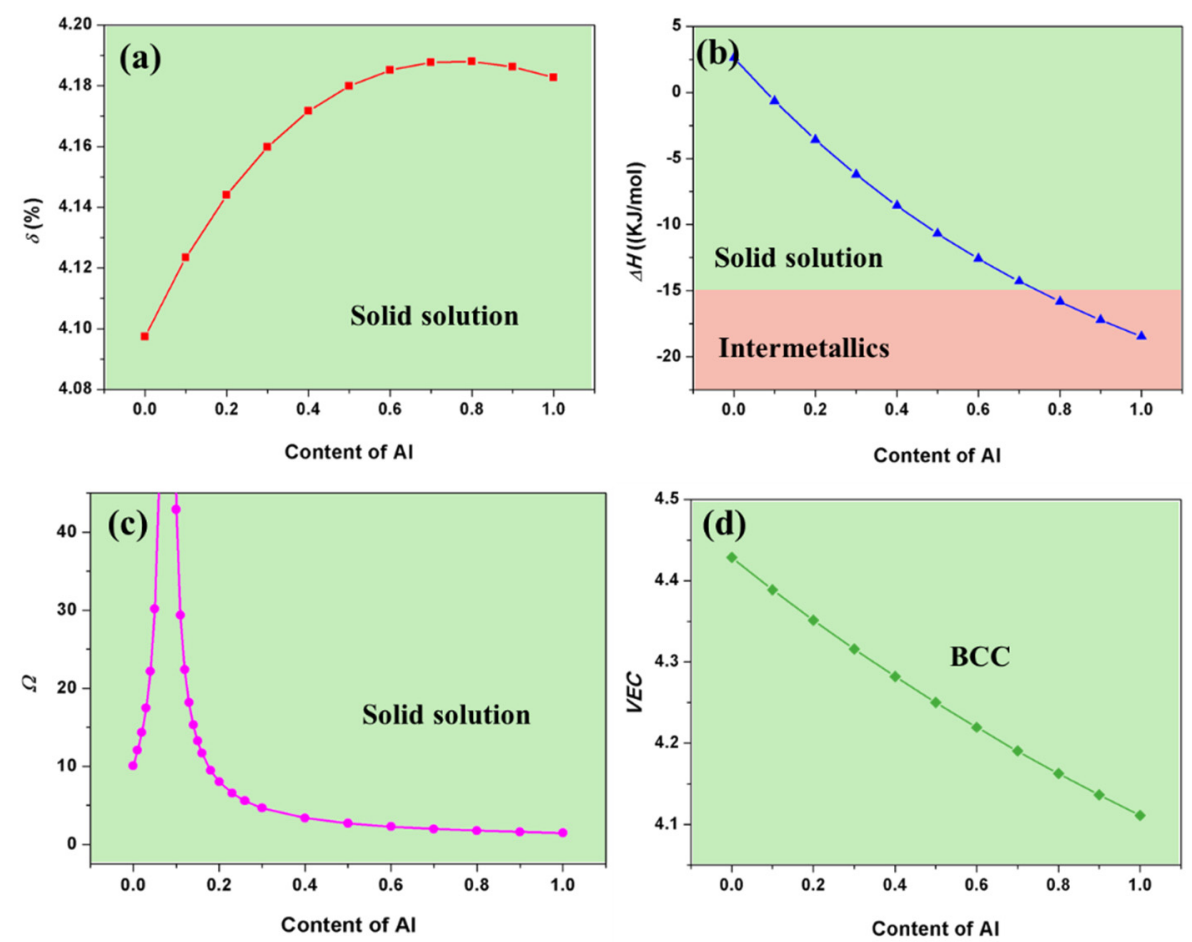

Figure 7. Calculation of empirical parameters for the Al-contained RHEAs: (a) atomic size mismatch $(\delta)$, (b) mixing of enthalpy $\left(\Delta H_{m i x}\right)$, (c) parameter $\Omega$, and (d) valence electron concentration $(V E C)$. 
Table 1. The values of $\Delta H_{\text {mix }}(\mathrm{kJ} / \mathrm{mol})$ for atomic pairs between elements in Ti-Nb-Ta-Zr-Al system [14].

\begin{tabular}{cccccc}
\hline Element & $\mathbf{T i}$ & $\mathbf{N b}$ & $\mathbf{T a}$ & $\mathbf{Z r}$ & $\mathbf{A l}$ \\
\hline $\mathrm{Ti}$ & - & - & - & - & - \\
$\mathrm{Nb}$ & 2 & - & - & - & - \\
$\mathrm{Ta}$ & 1 & 0 & - & - & - \\
$\mathrm{Zr}$ & 0 & 4 & 3 & - & - \\
$\mathrm{Al}$ & -30 & -18 & -19 & -44 & - \\
\hline
\end{tabular}

\section{Conclusions}

Precipitation behavior of the $\mathrm{TiNbTa}_{0.5} \mathrm{ZrAl}_{\mathrm{x}}$ RHEAs was investigated. Accordingly, the following conclusions can be drawn:

(1) The powder metallurgy TiNbTa $0.5 \mathrm{Zr}$ RHEA has single BCC structure. Addition of Al may lead to the formation of $\mathrm{Zr}_{5} \mathrm{Al}_{4}$ type intermetallic phase.

(2) The TiNbTa $0.5 \mathrm{ZrAl}_{\mathrm{x}} \mathrm{RHEAs}$ exhibit different precipitation behavior as a function of $\mathrm{Al}$ contents: for $\mathrm{x} \leq 0.2$, the RHEAs form $(\mathrm{Nb}, \mathrm{Ta})$-rich BCC2 precipitates and for $\mathrm{x} \geq 0.5$, the RHEAs mainly form ( $\mathrm{Zr}, \mathrm{Al})$-rich HCP precipitates.

(3) Annealing at $800{ }^{\circ} \mathrm{C}$ causes precipitation of an ordered $\mathrm{B} 2$ phase in $\mathrm{TiNbTa}_{0.5} \mathrm{ZrAl}_{0.5}$ RHEA, and the precipitation behavior is associated with spinodal decomposition. The ordered B2 precipitates have significant precipitation hardening effect on the $\mathrm{TiNbTa}_{0.5} \mathrm{ZrAl}_{0.5}$ RHEA.

Author Contributions: Conceptualization, J.W. and Y.C.; methodology, X.C. and Y.C.; formal analysis, X.C.; investigation, J.W. and N.L.; writing—original draft preparation, J.W.; writing-review \& editing, J.W., X.C., and Y.C.; funding acquisition, J.W. and Y.C. All authors have read and agreed to the published version of the manuscript.

Funding: This work was financially supported by the Natural Science Foundation of Hunan Province, China (2020JJ7058) and the Innovative Talents Project for Excellence in Postdoctoral Fellowship of Hunan Province (2020RC2007).

Institutional Review Board Statement: Not applicable.

Informed Consent Statement: Not applicable.

Data Availability Statement: Not applicable.

Conflicts of Interest: The authors declare no conflict of interest.

\section{References}

1. Cantor, B.; Chang, I.T.H.; Knight, P.; Vincent, A.J.B. Microstructural development in equiatomic multicomponent alloys. Mater. Sci. Eng. A 2004, 375-377, 213-218. [CrossRef]

2. Zhang, Y.; Zuo, T.T.; Tang, Z.; Gao, M.C.; Dahmen, K.A.; Liaw, P.K.; Lu, Z.P. Microstructures and properties of high-entropy alloys. Prog. Mater. Sci. 2014, 61, 1-93. [CrossRef]

3. Yeh, J.W.; Chen, S.K.; Lin, S.J.; Gan, J.Y.; Chin, T.S.; Shun, T.T.; Tsau, C.H.; Chang, S.Y. Nanostructured high-entropy alloys with multiple principal elements: Novel alloy design concepts and outcomes. Adv. Eng. Mater. 2004, 6, 299-303. [CrossRef]

4. Li, Z.; Pradeep, K.G.; Deng, Y.; Raabe, D.; Tasan, C.C. Metastable high-entropy dual-phase alloys overcome the strength-ductility trade-off. Nature 2016, 534, 227-230. [CrossRef]

5. Tsao, T.K.; Yeh, A.C.; Kuo, C.M.; Murakami, H. High temperature oxidation and corrosion properties of high entropy superalloys. Entropy 2016, 18, 62. [CrossRef]

6. Jin, K.; Lu, C.; Wang, L.M.; Qu, J.; Weber, W.J.; Zhang, Y.; Bei, H. Effects of compositional complexity on the ion-irradiation induced swelling and hardening in Ni-containing equiatomic alloys. Scripta Mater. 2016, 119, 65-70. [CrossRef]

7. Senkov, O.N.; Wilks, G.B.; Miracle, D.B.; Chuang, C.P.; Liaw, P.K. Refractory high-entropy alloys. Intermetallics 2010, 18, $1758-1765$. [CrossRef]

8. Miracle, D.B.; Senkov, O.N. A critical review of high entropy alloys and related concepts. Acta Mater. 2017, 122, 448-511. [CrossRef]

9. Regenberg, M.; Hasemann, G.; Wilke, M.; Halle, T.; Krüger, M. Microstructure evolution and mechanical properties of refractory Mo-Nb-V-W-Ti high-entropy alloys. Metals 2020, 10, 1530. [CrossRef] 
10. Senkov, O.N.; Gorsse, S.; Miracle, D.B. High temperature strength of refractory complex concentrated alloys. Acta Mater. 2019, 175, 394-405. [CrossRef]

11. Senkov, O.N.; Wilks, G.B.; Scott, J.M.; Miracle, D.B. Mechanical properties of Nb25Mo25Ta25W25 and V20Nb20Mo20Ta20W20 refractory high entropy alloys. Intermetallics 2011, 19, 698-706. [CrossRef]

12. Butler, T.M.; Chaput, K.J.; Dietrich, J.R.; Senkov, O.N. High temperature oxidation behaviors of equimolar NbTiZrV and NbTiZrCr refractory complex concentrated alloys (RCCAs). J. Alloy. Compd. 2017, 729, 1004-1019. [CrossRef]

13. Gorr, B.; Müller, F.; Azim, M.; Christ, H.-J.; Müller, T.; Chen, H.; Kauffmann, A.; Heilmaier, M. High-temperature oxidation behavior of refractory high-entropy alloys: Effect of alloy composition. Oxid. Met. 2017, 88, 339-349. [CrossRef]

14. Lin, C.M.; Juan, C.C.; Chang, C.H.; Tsai, C.W.; Yeh, J.W. Effect of Al addition on mechanical properties and microstructure of refractory AlxHfNbTaTiZr alloys. J. Alloy. Compd. 2015, 624, 100-107. [CrossRef]

15. Yurchenko, N.; Stepanov, N.; Tikhonovsky, M.; Salishchev, G. Phase evolution of the AlxNbTiVZr $(\mathrm{x}=0 ; 0.5 ; 1 ; 1.5)$ high entropy alloys. Metals 2016, 6, 298. [CrossRef]

16. Yurchenko, N.; Panina, E.; Tikhonovsky, M.; Salishchev, G.; Zherebtsov, S.; Stepanov, N. A new refractory Ti-Nb-Hf-Al high entropy alloy strengthened by orthorhombic phase particles. Int. J. Refract. Met. H. 2020, 92, 105322. [CrossRef]

17. Schuh, B.; Völker, B.; Maier-Kiener, V.; Todt, J.; Li, J.; Hohenwarter, A. Phase decomposition of a single-phase AlTiVNb highentropy alloy after severe plastic deformation and annealing. Adv. Eng. Mater. 2017, 19, 1600674. [CrossRef]

18. Ge, S.; Fu, H.; Zhang, L.; Mao, H.; Li, H.; Wang, A.; Li, W.; Zhang, H. Effects of Al addition on the microstructures and properties of MoNbTaTiV refractory high entropy alloy. Mater. Sci. Eng. A 2020, 784, 139275. [CrossRef]

19. Cao, Y.; Liu, Y.; Liu, B.; Zhang, W. Precipitation behavior during hot deformation of powder metallurgy Ti-Nb-Ta-Zr-Al high entropy alloys. Intermetallics 2018, 100, 95-103. [CrossRef]

20. Cao, Y.; Liu, Y.; Liu, B.; Zhang, W.; Wang, J.; Du, M. Effects of Al and Mo on high temperature oxidation behavior of refractory high entropy alloys. T. Nonferr. Metal. Soc. 2019, 29, 1476-1483. [CrossRef]

21. Senkov, O.; Isheim, D.; Seidman, D.; Pilchak, A. Development of a refractory high entropy superalloy. Entropy 2016, 18, 102. [CrossRef]

22. Senkov, O.N.; Jensen, J.K.; Pilchak, A.L.; Miracle, D.B.; Fraser, H.L. Compositional variation effects on the microstructure and properties of a refractory high-entropy superalloy AlMo0.5NbTa0.5TiZr. Mater. Des. 2018, 139, 498-511. [CrossRef]

23. Chen, S.Y.; Tong, Y.; Tseng, K.K.; Yeh, J.W.; Poplawsky, J.D.; Wen, J.G.; Gao, M.C.; Kim, G.; Chen, W.; Ren, Y.; et al. Phase transformations of HfNbTaTiZr high-entropy alloy at intermediate temperatures. Scripta Mater. 2019, 158, 50-56. [CrossRef]

24. Zhang, Y.; Yang, X.; Liaw, P.K. Alloy design and properties optimization of high-entropy alloys. JOM 2012, 64, 830-838. [CrossRef]

25. Zhang, Y.; Zhou, J.Y.; Lin, P.J.; Chen, L.G.; Liaw, K.P. Solid-solution phase formation rules for multi-component alloys. Adv. Eng. Mater. 2008, 10, 534-538. [CrossRef]

26. Guo, S.; Liu, C.T. Phase stability in high entropy alloys: Formation of solid-solution phase or amorphous phase. Prog. Nat. Sci. Mater. Int. 2011, 21, 433-446. [CrossRef]

27. Guo, S.; Ng, C.; Lu, J.; Liu, C.T. Effect of valence electron concentration on stability of fcc or bcc phase in high entropy alloys. J. Appl. Phys. 2011, 109, 103505. [CrossRef]

28. Yang, X.; Zhang, Y. Prediction of high-entropy stabilized solid-solution in multi-component alloys. Mater. Chem. Phys. 2012, 132, 233-238. [CrossRef]

29. Soni, V.; Gwalani, B.; Senkov, O.N.; Viswanathan, B.; Alam, T.; Miracle, D.B.; Banerjee, R. Phase stability as a function of temperature in a refractory high-entropy alloy. J. Mater. Res. 2018, 33, 1-12. [CrossRef]

30. Soni, V.; Gwalani, B.; Alam, T.; Dasari, S.; Zheng, Y.; Senkov, O.N.; Miracle, D.; Banerjee, R. Phase inversion in a two-phase, $\mathrm{BCC}+\mathrm{B} 2$, refractory high entropy alloy. Acta Mater. 2020, 185, 89-97. [CrossRef] 